\title{
Exploring Self-Compassion and Versions of Masculinity in Men Athletes
}

\author{
Nathan A. Reis, ${ }^{1}$ Kent C. Kowalski, ${ }^{1}$ Amber D. Mosewich, ${ }^{2}$ and Leah J. Ferguson ${ }^{1}$ \\ ${ }^{1}$ University of Saskatchewan; ${ }^{2}$ University of Alberta
}

\begin{abstract}
Despite a growing emphasis on self-compassion in sport, little research has focused exclusively on men athletes. The purpose of this research was to explore the interaction of self-compassion and diverse versions of masculinity on the psychosocial wellbeing of men athletes. The authors sampled 172 men athletes $\left(M_{\text {age }}=22.8 \mathrm{yr}\right)$ from a variety of sports, using descriptive methodology with self-report questionnaires. Self-compassion was related to most variables (e.g., psychological well-being, fear of negative evaluation, state self-criticism, internalized shame, reactions to a hypothetical sport-specific scenario) in hypothesized directions and predicted unique variance beyond self-esteem across most of those variables, as well as moderated relationships between masculinity and both autonomy and attitudes toward gay men. In addition, self-compassion was differentially related to inclusive and hegemonic masculinity. Our findings support self-compassion as a promising resource for men athletes to buffer emotionally difficult sport experiences.
\end{abstract}

Keywords: coping, male athletes, self-esteem, sport psychology

Although the benefits associated with sport participation have been well documented (e.g., Eime, Young, Harvey, Charity, \& Payne, 2013; Oja et al., 2015), many challenges associated with sport participation, such as negative evaluations by others and of oneself, can result in negative self-conscious emotions, emotional pain, difficult sporting experiences, and dropout (Mesagno, Harvey, \& Janelle, 2012; Mosewich, Kowalski, Sabiston, Sedgwick, \& Tracy, 2011). Therefore, it is critical that athletes have the skills to effectively cope with challenges in ways that enhance their overall sporting experience and minimize attrition rates.

One construct that has been associated with easing sport-specific setbacks and challenges is self-compassion, which is a warm and accepting way of treating oneself in the face of difficult experiences (Neff, 2003a, 2003b). Comprised of self-kindness, common humanity, and mindfulness, self-compassion was initially considered as a complement to self-esteem; however, self-compassion might offer unique advantages beyond those of self-esteem (Leary, Tate, Adams, Allen, \& Hancock, 2007; Mosewich et al., 2011), particularly because self-esteem is based largely on favorable self-evaluations compared with others (Cvencek, Fryberg, Covarrubias, \& Meltzoff, 2018). As many of the difficult experiences faced by athletes stem from evaluations, an evaluation-based resource like self-esteem seems counterintuitive; in addition, it is not always possible to evaluate oneself favorably compared with others, which is often where selfesteem fails (Leary et al., 2007). Alternatively, self-compassion is not rooted in evaluations and has been shown to be negatively related to emotional pain and a number of unhealthy and destructive emotions, thoughts, and behaviors (e.g., fear of negative evaluation, fear of selfcompassion, fear of failure, state rumination, concern over mistakes, state self-criticism, shame, negative affect, and passivity), as well as positively related to psychological well-being and constructive

Reis, Kowalski, and Ferguson are with the College of Kinesiology, University of Saskatchewan, Saskatoon, SK, Canada. Mosewich is with Faculty of Kinesiology, Sport, and Recreation, University of Alberta, Edmonton, AB, Canada. Reis (nathan. reis@usask.ca) is corresponding author. reactions (e.g., positivity, perseverance, responsibility) to emotionally difficult sport-specific scenarios (Ferguson, Kowalski, Mack, \& Sabiston, 2014, 2015; Mosewich, Crocker, Kowalski, \& DeLongis, 2013; Mosewich et al., 2011; Reis et al., 2015).

Although self-compassion has shown promise for easing the pain of women athletes' difficult experiences, men face distinct challenges in sport, often stemming from masculinity (Anderson \& McGuire, 2010). Whereas women athletes oftentimes face harsh evaluations that pit performance-based expectations against appearance-based expectations (e.g., carrying what might be considered excessive muscle mass, from a societal-based expectation of women's appearance, in order to excel at sport; Mosewich et al., 2013), men athletes' difficult experiences are often rooted in societal expectations of traditional masculine norms (e.g., strength and speed; Connell \& Messerschmidt, 2005). When men fail to meet traditional or "hegemonic" masculine standards in sport, where steep masculinity hierarchies and traditionally masculine behaviors are particularly overt and on display, they are often judged negatively by others and are susceptible to subordination and marginalization (Anderson \& McGuire, 2010; Connell \& Messerschmidt, 2005). Moreover, in part, because men athletes are more likely to hold hegemonic masculine beliefs and attitudes than men who are nonathletes (Wasylkiw \& Clairo, 2018), it is likely that men athletes who strongly value traditional masculine norms (e.g., self-reliance, hiding emotions) are even more likely to reject a construct like selfcompassion (Mosewich, Ferguson, McHugh, \& Kowalski, 2019), which involves treating oneself with kindness in the face of failure. In contrast to hegemonic masculinity, an alternative version of masculinity (i.e., inclusive masculinity) is premised on the horizontal alignment, or equal treatment, and acceptance of all representations and embodiments of masculinity (e.g., Anderson \& McGuire, 2010). In addition, inclusive masculinity is theorized to thrive in the absence of homophobia in sport, whereas hegemonic masculinity thrives in the presence of homophobia (Anderson \& McGuire, 2010). Perhaps men athletes who are more accepting of other men's masculinities are more likely to embrace a construct like selfcompassion, particularly compared with men athletes who adhere 
to traditional or hegemonic masculinity, because both are based on openness and acceptance (Neff, 2003a, 2003b).

In the wake of a sole focus on women athletes, there is a recent trend in sport self-compassion research to include both women athletes and men athletes, with encouraging findings (e.g., selfcompassion is positively related to adaptive coping, social support, well-being, and perfectionist strivings, and negatively related to shame and perfectionist concerns; Fontana, Fry, \& Cramer, 2017; Huysmans \& Clement, 2017; Jeon, Lee, \& Kwon, 2016; Lizmore, Dunn, \& Dunn, 2017). However, there are few self-compassion studies to date that have focused exclusively on men athletes and the unique challenges that men athletes face in sport, which oftentimes stem from masculinity. A notable exception is Wasylkiw and Clairo (2018), who found self-compassion and adherence to traditional masculine norms to be unrelated in populations of both men athletes and nonathletes. In their research, the levels of both self-compassion and adherence to traditional masculine norms were higher in men athletes compared with nonathletes. Higher levels of self-compassion also predicted help-seeking behavior in men athletes (but not nonathletes), indicating that self-compassion might enable men athletes to seek help when they encounter challenges, which is important because higher scores on traditional masculine norms were related to more negative attitudes toward help-seeking across groups (Wasylkiw \& Clairo, 2018). It is also important to note, however, that Wasylkiw and Clairo (2018) did not assess inclusive masculinity.

Studies involving samples exclusively comprised of men, albeit outside of the sport context (e.g., homosexual men, university-aged men), might shed additional light on whether self-compassion can be an effective resource for men athletes. The most promising findings in studies with these samples of men suggest that self-compassion is negatively related to a variety of destructive emotions and behaviors, including shame, self-stigma to help-seeking, and rumination, whereas it is positively related to self-esteem (Reid, Temko, Moghaddam, \& Fong, 2014; Reilly, Rochlen, \& Awad, 2013; Wasylkiw \& Clairo, 2018). Particularly relevant to our research, Reilly et al. (2013) found that men's shame levels moderated the relationship between hegemonic masculinity and self-compassion, such that when men had high levels of shame, there was no relationship between hegemonic masculinity and self-compassion, but when men had low levels of shame, there was a negative relationship between hegemonic masculinity and self-compassion. Interesting and unexplored questions that emerge from that research are whether higher levels of self-compassion could enable men of a hegemonic masculinity orientation to experience lower levels of shame and whether the inverse would be found for other versions of masculinity (e.g., inclusive masculinity). More specifically, is it possible that self-compassion moderates the relationship between masculinity and variables that are relevant to self-compassion research with men?

\section{The Current Research}

\section{Purpose}

Based on the above review, the purpose of our research was to explore the interaction of self-compassion and diverse versions of masculinity on the psychosocial well-being of men athletes. To address our purpose, we employed descriptive methodology with the use of self-report questionnaires, including self-compassion as the predictor variable throughout our analyses. Our psychosocial outcome variables/reactions were (a) all previously identified as related to self-compassion $(r>.40)$ in relevant populations (i.e., men athletes, women athletes, and men who are not athletes), (b) related to self-compassion in a sport-specific context (e.g., constructive and destructive reactions to a hypothetical emotionally difficult sport-specific scenario), and/or (c) measures of masculinity. The list of outcome variables/reactions is as follows: psychological well-being, constructive and destructive reactions to a hypothetical emotionally difficult sport-specific scenario, attitudes toward gay men, shame, self-stigma of seeking help, fear of failure, fear of negative evaluation, rumination, self-criticism, concern over mistakes, fear of compassion for self, hegemonic masculinity, and inclusive masculinity. In addition, using regression analysis, we aimed to determine whether relationships between self-compassion and the abovementioned variables/reactions remained after removing the influence of self-esteem, since self-esteem has been found to be related to self-compassion in samples of athletes (e.g., Mosewich et al., 2011). We also explored whether self-compassion moderates the relationship between masculinity (i.e., hegemonic, inclusive) and the remaining psychosocial outcome variables/reactions.

\section{Hypotheses}

Hypothesis 1. Self-compassion would be positively related to psychological well-being and constructive reactions (e.g., perseverance) to a hypothetical emotionally difficult sport-specific scenario and negatively related to potentially unhealthy variables (e.g., shame, selfcriticism) and destructive reactions (e.g., rumination) to the same hypothetical scenario. These relationships were hypothesized to remain significant after semipartialling out self-esteem.

Hypothesis 2. Self-compassion would be negatively related to hegemonic masculinity (i.e., masculine norm adherence) and positively related to inclusive masculinity. These relationships were also hypothesized to remain significant after semipartialling out self-esteem.

Hypothesis 3. We hypothesized that, when men athletes have high levels of self-compassion, negative relationships between hegemonic masculinity and psychological well-being and constructive reactions would be stronger than when men athletes have low self-compassion, whereas positive relationships between hegemonic masculinity and potentially unhealthy variables and destructive reactions would be weaker than for athletes with low self-compassion. Alternatively, we predicted that, when men athletes have high levels of selfcompassion, positive relationships between inclusive masculinity and psychological well-being and constructive reactions would be stronger than when men athletes have low self-compassion, whereas negative relationships between inclusive masculinity and potentially unhealthy variables and destructive reactions would be weaker than for athletes with low self-compassion.

\section{Methods}

\section{Participants}

The participants were 172 men athletes who had competed in a variety of individual and/or team sports (e.g., basketball, soccer, track and field, swimming, football, fencing) within 1 year prior to participation in the study. In total, 42 sports were represented, ranging from $n=1$ (e.g., boxing) to $n=40$ (i.e., soccer). All participants competed at a level of competition above recreational (i.e., local, provincial, regional, national, international) within the previous year and were between 16 and 35 years of age $\left(M_{\mathrm{age}}=\right.$ 22.8 years, $S D=4.7$ years). The majority of the participants selfidentified as White (78.8\%) 


\section{Measures}

An overview of all measures and their corresponding instruments can be found in Table 1 .

Self-Compassion. It was measured with the 26-item, 5-point Self-Compassion Scale (SCS; Neff, 2003a), ranging from 1 (almost never) to 5 (almost always) and consisting of six subscales, with three representing the overlying components of self-compassion (i.e., self-kindness, common humanity, mindfulness) and the other three representing their respective opposites (i.e., self-judgment, isolation, overidentification). Subscale means were used to create a composite self-compassion score.

Self-Esteem. It was measured with the Rosenberg Self-Esteem Scale (Rosenberg, 1965), which is a 10-item, 4-point scale from 1 (strongly disagree) to 4 (strongly agree). Part of the rationale for including self-esteem was so we could remove the variance accounted for by self-esteem from the relationships between self-compassion and other variables/reactions, which has been common practice in past research (e.g., Leary et al., 2007; Reis et al., 2015).

Psychological Well-Being. It was measured using the 84-item Scales of Psychological Well-Being (SPWB; Ryff \& Keyes, 1995), which is a 6-point measure ranging from 1 (strongly disagree) to 6 (strongly agree) and comprised of six subscales (i.e., positive relations with others, autonomy, environmental mastery, personal growth, purpose in life, self-acceptance). The subscales were scored individually and summed to create a composite.

Reactions to Sport-Specific Scenario. There were four sets of constructive reactions (i.e., self-compassionate, positivity, perseverance, responsibility) and three sets of destructive reactions (i.e., rumination, passivity, self-criticism) to a hypothetical emotionally difficult sport-specific scenario (i.e., "you are responsible for losing an athletic competition for your team") measured on a scale from 1 (not at all) to 6 (extremely). The hypothetical scenario was initially rated from 1 (not at all) to 6 (extremely) on perceived emotional difficulty. There were four self-compassionate items

\section{Table 1 Variables and Instruments}

\begin{tabular}{ll}
\hline Variable & Instrument \\
\hline Self-compassion & Self-Compassion Scale (Neff, 2003a) \\
Self-esteem & Rosenberg Self-Esteem Scale (Rosenberg, 1965) \\
Psychological well-being & 84-Item Scales of Psychological Well-Being (Ryff \& Keyes, 1995) \\
Hypothetical emotionally difficult sport-specific & "You are responsible for losing an athletic competition for your team" (Leary \\
scenario & et al., 2007) \\
Constructive reactions to hypothetical emotionally & In response to hypothetical scenario "You are responsible for losing an athletic \\
difficult sport-specific scenario: & competition for your team" \\
Self-compassion & -Constructive reactions to scenario (Ferguson et al., 2015; Leary et al., 2007)
\end{tabular}

Positivity

Perseverance

Responsibility

Attitudes toward gay men

Attitudes Toward Gay Men revised subscale (Herek, 1997) of the Attitudes Toward Lesbians and Gay Men Scale (Herek, 1984)

Shame Shame subscale of the Internalized Shame Scale (del Rosario \& White, 2006)

Self-stigma of seeking help Self-Stigma of Seeking Help Scale (Vogel, Wade, \& Haake, 2006)

Fear of failure Sport-adapted version of the Performance Failure Appraisal Inventory (Conroy, Willow, \& Metzler, 2002)

Fear of negative evaluation

Fear of Negative Evaluation Scale (Leary, 1983)

Rumination

Response to "the most significant negative event in sport over the past week that was personally demanding (such as setback or failure)" (Puterman, DeLongis, \& Pomaki, 2010) ${ }^{\mathrm{a}}$

Self-criticism

Concern over mistakes

Response to "the most significant negative event in sport over the past week that was personally demanding (such as setback or failure)" (Gilbert \& Procter, 2006) ${ }^{\mathrm{a}}$

Fear of compassion for self

Concern over Mistakes subscale of the Sport Multidimensional Perfectionism Scale-2 (Gotwals \& Dunn, 2009)

Fear of Compassion for Self subscale of the Fears of Compassion Scales (Gilbert, McEwan, Matos, \& Rivis, 2011)

Destructive reactions to hypothetical emotionally

difficult sport-specific scenario:

Rumination

In response to hypothetical scenario "You are responsible for losing an athletic competition for your team"

Passivity

Self-criticism

Inclusive masculinity

-Destructive reactions to scenario (Ferguson et al., 2015)

Hegemonic masculinity

Inclusive Masculinity Theory Scale (created for this study) Conformity to Masculine Norms Inventory (Parent \& Moradi, 2009)

Note. Item composites for all scales/measures were used in the analyses, with the exception of the Self-Compassion Scale, which was derived from the six subscale means. The Scales of Psychological Well-Being and Conformity to Masculine Norms Inventory were also derived from the subscales.

${ }^{\text {a }}$ Sport-specific adaptation of original scenario (Mosewich et al., 2013). 
(e.g., "I would keep the situation in perspective") and two items for each of the other constructive reactions (positivity-e.g., "I would focus on positive things"; perseverant-e.g., "I would strive for something more"; and responsibility-e.g., "I would take responsibility to rectify the situation") and each of the destructive reactions (ruminative-e.g., "I would dwell on the situation"; passive-e.g., "I would just give up"; and self-critical-e.g., "I would be very critical of myself"). These reactions were based on the underlying mechanisms of self-compassion identified by Ferguson et al. (2015) and the self-compassionate reactions developed by Leary et al. (2007). All of the reactions were included to provide a state measure of how men athletes react to a sport-specific, emotionally difficult scenario. Particularly important to our study, the self-compassionate reactions were intended to measure state self-compassion, whereas the SCS measures more of a trait self-compassion.

Potentially Unhealthy Variables. There were nine potentially unhealthy variables (i.e., attitudes toward gay men, shame, selfstigma of seeking help, fear of failure, fear of negative evaluation, rumination, self-criticism, concern over mistakes, and fear of compassion for self). Attitudes toward gay men was measured with the five-item Attitudes Toward Gay Men revised subscale (i.e., ATG-R-S5; Herek, 1997) of the Attitudes Toward Lesbians and Gay Men Scale (Herek, 1984), ranging from 1 (strongly disagree) to 5 (strongly agree), which was included as a potentially unhealthy outcome variable related to masculinity. Shame was measured with the 24-item Shame Subscale of the Internalized Shame Scale (ISS; del Rosario \& White, 2006). The ISS is a 5-point scale ranging from 0 (never) to 4 (almost always). Self-stigma of seeking help was measured with the Self-Stigma of Seeking Help Scale (Vogel et al., 2006), which is a 10-item, 5-point scale ranging from 1 (strongly disagree) to 5 (strongly agree). Fear of failure was assessed with a sport-specific, five-item adapted version of the Performance Failure Appraisal Inventory (Conroy et al., 2002), ranging from -2 (do not believe at all) to +2 (believe $100 \%$ of the time). Fear of negative evaluation was measured with the 12-item Fear of Negative Evaluation Scale (Leary, 1983), which is a 12item, 5-point scale ranging from 1 (not at all characteristic of me) to 5 (extremely characteristic of me). Rumination, self-criticism, and concern over mistakes were all measured with altered, sportspecific versions of their respective original scales (i.e., rumination -Puterman et al., 2010; self-criticism-Gilbert \& Procter, 2006; concern over mistakes-Gotwals \& Dunn, 2009), as adapted by Mosewich et al. (2013). Rumination was assessed using three items on a 5-point scale, ranging from 1 (not at all) to 5 (a lot), in response to "the most significant negative event in sport over the past week that was personally demanding (such as setback or failure)." Self-criticism was measured with seven items on a 5-point scale ranging from 1 (not at all) to 10 (very) in response to the prompt, "think about the most significant negative event in sport over the past week that was personally demanding (such as setback or failure)" (Mosewich et al., 2013). Concern over mistakes was assessed with the eight-item, 5-point scale, ranging from 1 (strongly disagree) to 5 (strongly agree; Concern over Mistakes subscale of the Sport Multidimensional Perfectionism Scale-2; Gotwals \& Dunn, 2009). Fear of compassion for self was measured with the 15-item, 5-point Fear of Compassion for Self subscale of the Fears of Compassion Scales (Gilbert et al., 2011), ranging from 0 (don't agree at all) to 4 (completely agree).

Masculinity Variables. There were two masculinity variables measured (i.e., inclusive masculinity, hegemonic masculinityconformity to masculine norms). Inclusive masculinity was measured with the Inclusive Masculinity Theory Scale (IMT), which was developed for this study, in accordance with direction and guidance from Dr. Eric Anderson (E. Anderson, personal communication, May-December, 2017), a leading theorist in the field.

The IMT is a 10-item, 5-point scale from 1 (strongly disagree) to 5 (strongly agree), comprised of five 2-item subscales (i.e., attitudes toward homosexuality, emotional intimacy, physical touch, acceptability of masculine appearance, and attitudes toward aggression and fighting). The attitudes toward homosexuality items are as follows: "I feel comfortable being around males, regardless of their sexual orientation (i.e., straight, bisexual, or gay)" and "I do not pass judgment on males, based on their sexual orientation (i.e., straight, bisexual, or gay)." The emotional intimacy items are as follows: "If I were to endure a difficult experience (e.g., the death of a loved one), I would be able to cry around at least one of my male friends" and "When I go through difficult times and/or experiences, I am able to discuss my emotions about the challenging event with at least one of my male friends." The physical touch items are as follows: "I have no hesitation or reluctance to physically embrace another male by hugging him" and "I have no hesitation or reluctance to physically embrace another male by kissing him on the cheek if it were culturally appropriate (e.g., in parts of Europe)." The acceptability of masculine appearance items are as follows: "I think no less of males who wear pink or purple clothes, compared to other males" and "I think no less of males who take a long time to get ready (e.g., before going to the bar), compared to males who get ready quickly." The attitudes toward aggression and fighting items are as follows: "When possible, it is best to avoid physical confrontation (e.g., fighting)" and "I try to resolve the conflict in a calm, civilized manner, instead of turning to violence." The IMT was developed to address each of the overlying areas that Dr. Anderson recommended be considered when measuring inclusive masculinity.

Hegemonic masculinity was measured with the 46-item, 4-point Conformity to Masculine Norms Inventory (CMNI-46; Parent \& Moradi, 2009), ranging from 1 (strongly disagree) to 4 (strongly agree), and consisting of nine subscales (i.e., winning, emotional control, violence, primacy of work, risk-taking, heterosexual self-presentation, playboy, self-reliance, and power over women). The subscales were scored individually and summed to create a composite score.

All measures have previously been supported by construct validity evidence and shown to be internally reliable at $\alpha \geq .80$ in populations relevant to men athletes (e.g., women athletes, nonathlete samples of men), with the exception of the IMT, which was developed for this study. In this study, the IMT was found to be internally reliable at $\alpha=.81$.

\section{Procedure}

After receiving ethical approval from a university behavioral research ethics board, men athletes were recruited to participate through a variety of avenues (e.g., provincial sport organization, online university posts). The participants visited a link to an online survey, which began with an informed consent form, followed by a brief demographic survey. The participants then completed the following measures: SCS, the Rosenberg Self-Esteem Scale, the SPWB, the IMT, the Attitudes Toward Gay Men revised subscale, items pertaining to the hypothetical scenario, the CMNI, the ISS, the Self-Stigma of Seeking Help Scale, the Sport adapted version of the Performance Failure Appraisal Inventory, the Fear of Negative 
Evaluation Scale, state rumination, state self-criticism, concern over mistakes, and fear of compassion for self. Upon completion of all measures, the participants were provided with an online debrief and thanked for their participation, before being redirected away from the survey. The participants who completed the survey were mailed a \$10 gift card.

\section{Data Analysis}

The participants with more than two missing data points on any individual scale or subscale (Tabachnick \& Fidell, 2013) were deleted from the data set $(n=56)$, resulting in the final sample size of 172 used in all subsequent analyses. Aligning with research in the field of self-compassion and sport (e.g., Ferguson et al., 2015; Reis et al., 2015), within-person mean substitution was used to replace missing data, with 68 participants having at least one data point replaced. According to Parent (2013), when handling itemlevel missing data, the method makes little difference, which further justifies mean substitution as a simple method to apply. Also, five scales (i.e., SCS, SPWB, IMT, Attitudes Toward Gay Men revised subscale, ISS) violated normality assumptions, in addition to 13 subscales, six 2-item measures, and one single-item measure. The appropriate data transformations (e.g., square root, logarithm, inverse) performed on the nonparametric data resulted in no substantive changes to the results, so the original data were used for ease of interpretation. To test both Hypothesis 1 and Hypothesis 2, the relationships between self-compassion and other variables/reactions were examined with Pearson correlations, and semipartial correlations were used to remove the influence of self-esteem on the relationships between self-compassion and other variables/reactions.

Hypothesis 3 was tested using hierarchical regression analyses. To examine whether self-compassion moderated the relationships between hegemonic masculinity and other variables/reactions, hegemonic masculinity and self-compassion were entered in the first step of the analyses, whereas in the second step, the interaction term between hegemonic masculinity and self-compassion was entered. To examine whether self-compassion moderated the relationships between inclusive masculinity and other variables/reactions, inclusive masculinity and self-compassion were entered in the first step of the analyses, whereas in the second step, the interaction term between inclusive masculinity and self-compassion was entered. For significant interactions, post hoc probing followed the procedures outlined by Aiken and West (1991), which included plotting significant interactions and testing if the slopes of the lines differ from zero. To further interpret the meaning of significant interaction effects, post hoc probing included creating regression lines for high (1 SD above the mean), average, and low (1SD below the mean) self-compassion.

\section{Results}

\section{Descriptive Statistics and Scale Reliabilities}

Descriptive statistics and internal consistency scale reliabilities are reported in Table 2.

\section{Hypothesis Testing}

Hypothesis 1. As hypothesized, self-compassion was positively related to psychological well-being and all constructive reactions $(p<.05)$ and negatively related to all potentially unhealthy variables and all destructive reactions $(p<.05)$, except for attitudes toward gay men, as shown in Table 3 . In addition, self-compassion was positively related to each of the six subscales of the SPWB. After semipartialling out self-esteem, self-compassion remained positively related to psychological well-being $(1.1 \%$ unique variance) and each of the following constructive reactions to the hypothetical emotionally difficult sport-specific scenario: selfcompassionate reactions ( $22.1 \%$ unique variance), positive reactions (22.1\% unique variance), and perseverant reactions (6.4\% unique variance). The positive relationships between self-compassion and two of the SPWB subscales (i.e., positive relations with others, self-acceptance) also remained significant after semipartialling out self-esteem. As predicted, after semipartialling out self-esteem, selfcompassion remained negatively related to each of the following destructive reactions to the hypothetical emotionally difficult sportspecific scenario: ruminative reactions ( $14.3 \%$ unique variance) and self-critical reactions (20.6\% unique variance). Also, as predicted, upon semipartialling out self-esteem, self-compassion remained negatively related to internalized shame (5.1\% unique variance), fear of failure (9.3\% unique variance), fear of negative evaluation $(7.7 \%$ unique variance), state rumination ( $18.8 \%$ unique variance), state selfcriticism (12.3\% unique variance), concern over mistakes $(11.4 \%$ unique variance), and fear of compassion for self (2.2\% unique variance). All semipartial correlation values can be found in Table 3.

Hypothesis 2. As hypothesized, self-compassion was negatively related to hegemonic masculinity and positively related to inclusive masculinity (see Table 3). Also, self-compassion was negatively related to several of the CMNI subscales (i.e., emotional control, violence, self-reliance) and each of the five IMT subscales. After semipartialling out self-esteem, self-compassion remained negatively related to hegemonic masculinity (3.7\% unique variance). However, the positive relationship between self-compassion and inclusive masculinity did not remain after semipartialling out self-esteem. It should also be noted that the relationships between self-compassion and several of the Conformity to Masculine Norm Inventory subscales (i.e., emotional control, violence, and self-reliance) remained after semipartialling out self-esteem. In addition, although the Winning subscale of the CMNI was not initially related to self-compassion, it became negatively related to self-compassion after semipartialling out self-esteem. All semipartial correlation values can be found in Table 3.

Hypothesis 3. Self-compassion did not moderate the relationship between hegemonic masculinity and psychological well-being or any of the constructive reactions. However, when considering subscales of the SPWB, self-compassion moderated the relationship between hegemonic masculinity and the autonomy subscale. When men athletes had higher levels of self-compassion, the negative relationship between hegemonic masculinity and autonomy was stronger than when men athletes had lower levels of self-compassion (see Figure 1; Table 4). Self-compassion also moderated the relationship between hegemonic masculinity and (negative) attitudes toward gay men. When men athletes had lower levels of self-compassion, the positive relationship between hegemonic masculinity and (negative) attitudes toward gay men was stronger than when men athletes had higher levels of self-compassion (see Figure 1; Table 4).

Self-compassion did not moderate the relationship between inclusive masculinity and psychological well-being or any of the constructive reactions that we tested. When considering individual subscales of the SPWB, self-compassion moderated the relationship between inclusive masculinity and the autonomy subscale. When men athletes had higher levels of self-compassion, the positive relationship between inclusive masculinity and autonomy was stronger than when men athletes had lower levels of self-compassion (see Figure 1; Table 4). Self-compassion also moderated the 
Table 2 Descriptive Statistics and Scale Reliabilities

\begin{tabular}{|c|c|c|c|c|c|}
\hline Variable & No. of Items & Scale range & $M$ & $S D$ & Reliability $\alpha$ \\
\hline Self-compassion (SCS) & 26 & 1 to 5 & 3.11 & 0.65 & .92 \\
\hline Self-esteem (RSES) & 10 & 10 to 40 & 31.05 & 5.43 & .89 \\
\hline Psychological well-being (SPWB) & 84 & 84 to 504 & 368.49 & 57.05 & .97 \\
\hline Positive relations with others & 14 & 14 to 84 & 60.82 & 12.09 & .87 \\
\hline Autonomy & 14 & 14 to 84 & 58.30 & 9.45 & .80 \\
\hline Environmental mastery & 14 & 14 to 84 & 59.87 & 11.47 & .88 \\
\hline Personal growth & 14 & 14 to 84 & 66.03 & 10.17 & .87 \\
\hline Purpose in life & 14 & 14 to 84 & 63.12 & 11.64 & .89 \\
\hline Self-acceptance & 14 & 14 to 84 & 60.15 & 13.99 & .93 \\
\hline Inclusive masculinity (IMT) & 10 & 10 to 50 & 40.62 & 6.79 & .81 \\
\hline Attitudes toward gay men (ATG-R-S5) & 5 & 5 to 25 & 9.74 & 5.75 & .93 \\
\hline Hypothetical reaction & 1 & 1 to 6 & 4.67 & 1.17 & - \\
\hline Reactions: Self-compassion & 4 & 4 to 24 & 11.66 & 4.65 & .84 \\
\hline Reactions: Positive & 2 & 2 to 12 & 5.80 & 2.75 & .88 \\
\hline Reactions: Perseverant & 2 & 2 to 12 & 8.93 & 2.29 & .71 \\
\hline Reactions: Responsible & 2 & 2 to 12 & 9.95 & 2.11 & .89 \\
\hline Reactions: Ruminative & 2 & 2 to 12 & 8.26 & 2.74 & .84 \\
\hline Reactions: Passive & 2 & 2 to 12 & 2.96 & 2.06 & .93 \\
\hline Reactions: Self-critical & 2 & 2 to 12 & 8.76 & 2.76 & .93 \\
\hline Hegemonic masculinity (CMNI) & 46 & 0 to 138 & 67.04 & 12.71 & .84 \\
\hline Winning & 6 & 0 to 18 & 12.38 & 3.46 & .83 \\
\hline Emotional control & 6 & 0 to 18 & 9.19 & 3.36 & .87 \\
\hline Risk-taking & 5 & 0 to 15 & 7.57 & 2.62 & .81 \\
\hline Violence & 6 & 0 to 24 & 10.34 & 3.38 & .82 \\
\hline Power over women & 4 & 0 to 12 & 3.02 & 2.49 & .83 \\
\hline Playboy & 4 & 0 to 12 & 4.91 & 2.67 & .72 \\
\hline Self-reliance & 5 & 0 to 15 & 6.73 & 2.86 & .85 \\
\hline Primacy of work & 4 & 0 to 12 & 5.02 & 2.37 & .80 \\
\hline Heterosexual self-presentation & 6 & 0 to 18 & 7.87 & 4.47 & .90 \\
\hline Internalized shame (ISS) & 24 & 0 to 96 & 31.22 & 21.08 & .97 \\
\hline Self-stigma of seeking help (SSOSH) & 10 & 10 to 50 & 27.02 & 7.31 & .86 \\
\hline Fear of failure (PFAI) & 5 & -10 to 10 & -0.83 & 4.55 & .84 \\
\hline Fear of negative evaluation (FNE) & 12 & 12 to 60 & 33.84 & 11.61 & .96 \\
\hline State rumination & 3 & 3 to 15 & 9.77 & 3.46 & .89 \\
\hline State self-criticism & 7 & 7 to 70 & 37.10 & 12.60 & .83 \\
\hline Concern over mistakes & 8 & 8 to 40 & 24.47 & 6.47 & .86 \\
\hline Fear of compassion for self & 15 & 0 to 60 & 22.52 & 13.13 & .95 \\
\hline
\end{tabular}

Note. SCS = Self-Compassion Scale; RSES = Rosenberg Self-Esteem Scale; SPWB = Scales of Psychological Well-Being; IMT = Inclusive Masculinity Theory Scale; ATG-R-S5 = Attitudes Toward Gay Men revised subscale; CMNI = Conformity to Masculine Norms Inventory; ISS = Internalized Shame Scale; SSOSH = Self-Stigma of Seeking Help Scale; PFAI = Performance Failure Appraisal Inventory; FNE = Fear of Negative Evaluation.

relationship between inclusive masculinity and (negative) attitudes toward gay men. When men athletes had lower levels of selfcompassion, the negative relationship between inclusive masculinity and (negative) attitudes toward gay men was stronger than when men athletes had higher levels of self-compassion (see Figure 1; Table 4).

\section{Discussion}

The purpose of this research was to explore the interaction of self-compassion and diverse versions of masculinity on the psychosocial well-being of men athletes. Our results show that self-compassion is positively related to psychological well-being (and each of its six subscales) and self-compassionate, positive, perseverant, and responsible reactions to a hypothetical emotionally difficult sport-specific scenario. Self-compassion was also negatively related to all of the potentially unhealthy variables we tested (i.e., shame, self-stigma of seeking help, fear of failure, fear of negative evaluation, rumination, self-criticism, concern over mistakes, fear of compassion for self), with the exception of attitudes toward gay men, as well as to ruminative, passive, and self-critical reactions to a hypothetical emotionally difficult 
Table 3 Correlations and Semipartial Correlations

\begin{tabular}{|c|c|c|}
\hline Variable & Self-compassion (SCS) & Self-esteem (RSES) \\
\hline Psychological well-being (SPWB) & $.66 * * / .10 *$ & $.84 * * / .53 * *$ \\
\hline Positive relations with others & $.60 * * / .19 * *$ & $.66^{* *} / .35^{* *}$ \\
\hline Autonomy & $.45^{* *} / .12$ & $.52 * * / .29 * *$ \\
\hline Environmental mastery & $.59 * * / .09$ & $.76^{* *} / .48 * *$ \\
\hline Personal growth & $.39 * * / .02$ & $.55 * * / .38 * *$ \\
\hline Purpose in life & $.51 * * /-.02$ & $.75 * * / .55 * *$ \\
\hline Self-acceptance & $.67 * * / .11 * *$ & $.85 * * / .53 * *$ \\
\hline Inclusive masculinity (IMT) & $.30 * * / .08$ & $.35 * * / .19 *$ \\
\hline Attitudes toward homosexuality & $.18 * * / .06$ & $.20 * * / .10$ \\
\hline Emotional intimacy & $.29 * * / .11$ & $.31 * * / .15^{*}$ \\
\hline Physical touch & $.20 * * / .07$ & $.21 * * / .10$ \\
\hline Acceptability of masculine appearance & $.16 * /-.01$ & $.24 * * / .18 *$ \\
\hline Attitudes toward aggression and fighting & $.21 * * / .05$ & $.25 * * / .15 *$ \\
\hline Attitudes toward gay men (ATG-R-S5) & $-.09 /-.01$ & $-.12 /-.08$ \\
\hline Hypothetical scenario $(N=168)$ & $-.20 * * /-.22 * *$ & $-.07 / .11$ \\
\hline Reactions: Self-compassion & $.59 * * / .47 * *$ & $.36 * * /-.07$ \\
\hline Reactions: Positive & $.57 * * / .47 * *$ & $.33 * * /-.09$ \\
\hline Reactions: Perseverant & $.46 * * / .25^{* *}$ & $.39 * * / .11$ \\
\hline Reactions: Responsible & $.21 * * / .00$ & $.30 * * / .21 * *$ \\
\hline Reactions: Ruminative & $-.52 * * /-.38 * *$ & $-.36 * * / .01$ \\
\hline Reactions: Passive & $-.25 * * / .10$ & $-.45 * * /-.40 * *$ \\
\hline Reactions: Self-critical & $-.54 * * /-.45 * *$ & $-.31 * * / .10$ \\
\hline Hegemonic masculinity (CMNI) & $-.32 * * /-.19 * *$ & $-.26 * * /-.05$ \\
\hline Winning & $-.11 /-.30 * *$ & $.15 * / .32 * *$ \\
\hline Emotional control & $-.31 * * /-.22 * *$ & $-.22 * * / .00$ \\
\hline Risk-taking & $-.04 / .08$ & $-.13 * /-.14$ \\
\hline Violence & $-.22 * * /-.26 * *$ & $-.05 / .15$ \\
\hline Power over women & $-.08 / .08$ & $-20 * * /-.20 * *$ \\
\hline Playboy & $-.11 / .08$ & $-.25 * * /-.24 * *$ \\
\hline Self-reliance & $-.34 * * /-.16 *$ & $-.32 * * /-.12$ \\
\hline Primacy of work & $-.04 / .07$ & $-.14 * /-.15$ \\
\hline Heterosexual self-presentation & $-.04 /-.03$ & $-.03 / .00$ \\
\hline Internalized shame (ISS) & $-.74 * * /-.23 * *$ & $-.82 * * /-.43 * *$ \\
\hline Self-stigma of seeking help (SSOSH) & $-.21 * * /-.14$ & $-.16 * /-.02$ \\
\hline Fear of failure (PFAI) & $-.63 * * /-.31 * *$ & $-.58 * * /-.20 * *$ \\
\hline Fear of negative evaluation (FNE) & $-.54 * * /-.28 * *$ & $-.49 * * /-.16^{*}$ \\
\hline State rumination & $-.57 * * /-.43 * *$ & $-.37 * * / .04$ \\
\hline State self-criticism & $-.52 * * /-.35 * *$ & $-.38 * * /-.03$ \\
\hline Concern over mistakes & $-.56 * * /-.34 * *$ & $-.45 * * /-.09$ \\
\hline Fear of compassion for self & $-.49 * * /-.15 *$ & $-.55^{* * /-} .29 * *$ \\
\hline
\end{tabular}

Note. The relationships are presented using the following format: Pearson correlation/semipartial correlation with the influence of the other predictor removed. SCS = Self-Compassion Scale; RSES = Rosenberg Self-Esteem Scale; SPWB = Scales of Psychological Well-Being; IMT = Inclusive Masculinity Theory Scale; ATG-R-S5 = Attitudes Toward Gay Men revised subscale; CMNI = Conformity to Masculine Norms Inventory; ISS = Internalized Shame Scale; SSOSH = SelfStigma of Seeking Help Scale; PFAI = Performance Failure Appraisal Inventory; FNE = Fear of Negative Evaluation. $* p<.05$. ** $p<.01$.

sport-specific scenario. Therefore, it seems likely that selfcompassion is associated with many of the same benefits for men athletes as it is for women athletes (e.g., decreased shame, increased overall psychological well-being; Ferguson et al., 2014, 2015; Mosewich et al., 2011). Moreover, by replicating many of the past findings in self-compassion research with women athletes and nonathlete samples of men, we have identified variables and reactions that might be important to focus on in future selfcompassion research with men athletes specifically.

Our research is unique in that we tested for potential relationships between self-compassion and variables/reactions not previously examined in men athletes (e.g., psychological well-being, 


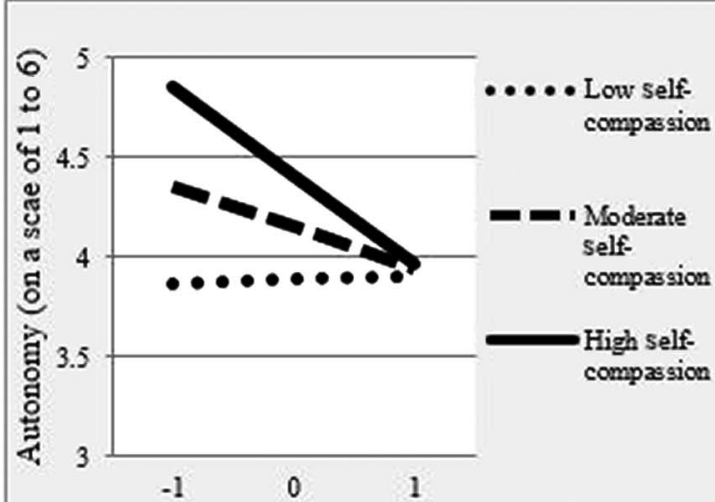

Hegemonic masculinity ( -1 to $1 S D)$

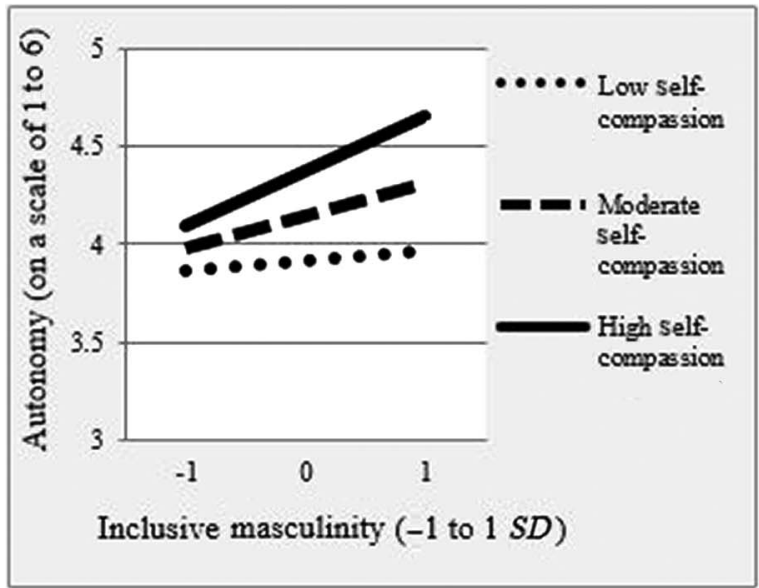

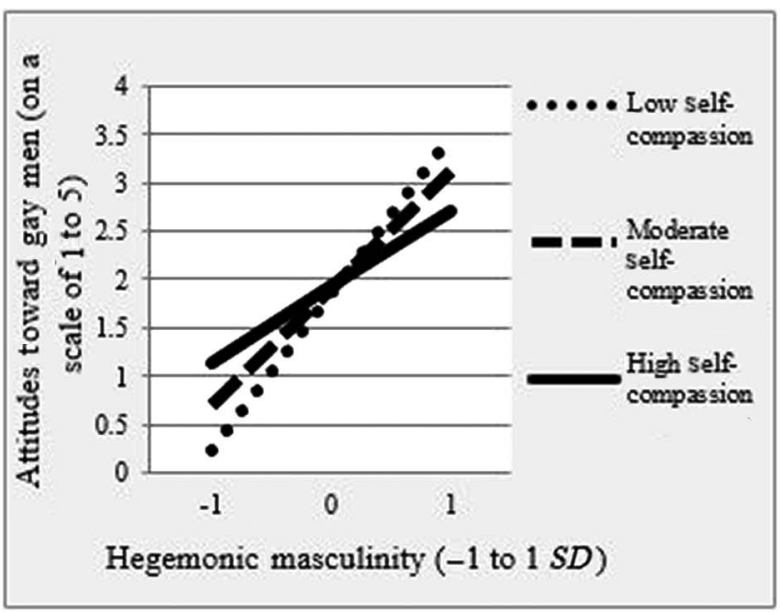

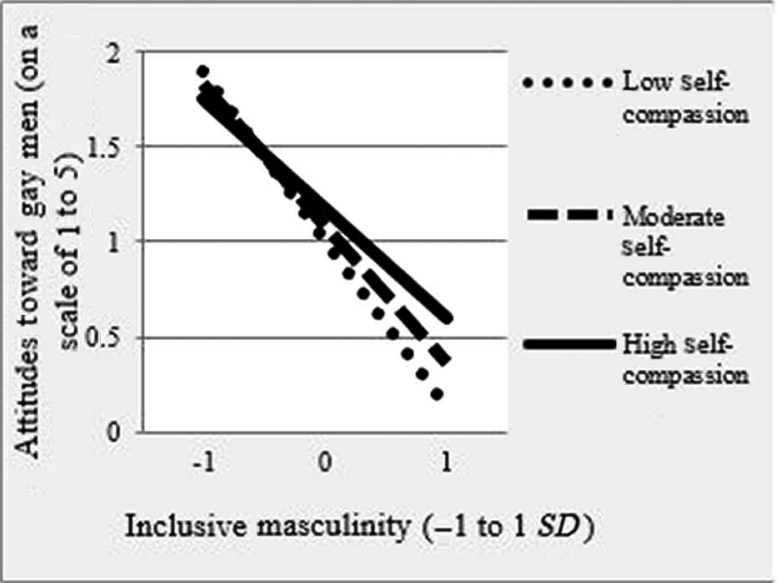

Figure 1 - Visual representation of all significant moderation analyses, where self-compassion is the moderating variable.

fear of failure, constructive and destructive reactions to a hypothetical emotionally difficult sport-specific scenario) and found that self-compassion predicts variance beyond self-esteem for the majority of the higher order variables/reactions we tested. This is important because there is currently a small body of literature on men athletes and self-compassion, and our results further support the potential utility of self-compassion as a useful coping resource in sport, particularly one above and beyond self-esteem (e.g., Mosewich et al., 2011; Reis et al., 2015).

Perhaps the most novel contribution of our research to the literature is that we explored relationships between self-compassion and different versions of masculinity (i.e., inclusive masculinity, hegemonic masculinity). While Reilly et al. (2013) found that self-compassion was negatively related to hegemonic masculinity and that shame moderated that relationship, their research was not specific to men athletes. Alternatively, Wasylkiw and Clairo (2018) found no relationship between self-compassion and hegemonic masculinity in a population of exclusively men athletes, but they did not explore any relationships between self-compassion and other forms of masculinity (e.g., inclusive masculinity). Thus, our findings that self-compassion is negatively related to hegemonic masculinity and positively related to inclusive masculinity in a population of exclusively men athletes are new and substantial contributions to the literature because the link between self-compassion and masculinity seems to depend on the versions of masculinity endorsed. Likewise, our finding that self-compassion moderates the relationships between the differing versions of masculinity (i.e., inclusive, hegemonic) and both autonomy and attitudes toward gay men, in theoretically healthy ways, is also unique to the literature.

Although the specific implications of our self-compassion and masculinity findings are not yet clear, it seems likely that men athletes who align with traditional masculine norms (e.g., aggression, dominance; Connell \& Messerschmidt, 2005; Reilly et al., 2013) will have significant barriers to accessing or using self-compassion as a resource to help them deal with challenges in sport, which Mosewich et al. (2019) anticipated would be a likely outcome. Alternatively, men athletes who align with inclusive masculine norms (e.g., understanding and acceptance of all representations of masculinity; Anderson \& McGuire, 2010) appear to be well situated to have self-compassion more readily accessible when experiencing sportbased challenges. Accordingly, although men athletes who endorse a hegemonic masculinity orientation might have the most to gain by increasing their self-compassion levels, especially considering they seemingly have more unhealthy traits and tendencies (e.g., higher levels of shame, self-criticism, destructive reactions) than men of an inclusive masculinity orientation, paradoxically, it could be more difficult because hegemonic-oriented men might be more likely to also reject self-compassion (Reilly et al., 2013).

Further insight into the possible role of self-compassion in shaping the impact of versions of masculinity can be gained from 
Table 4 Significant Moderation Analyses

\begin{tabular}{|c|c|c|c|c|c|}
\hline Criterion variable & $B$ & SE B & $\beta$ & $R^{2}$ & $\Delta R^{2}$ \\
\hline \multicolumn{6}{|c|}{ Autonomy subscale of the SPWB } \\
\hline Step 1 & & & & $.22 * *$ & $.22 * *$ \\
\hline Hegemonic masculinity & -0.31 & 0.17 & -0.13 & & \\
\hline Self-compassion & 0.41 & 0.07 & $0.41 * *$ & & \\
\hline Step 2 & & & & $.24 *$ & $.02 *$ \\
\hline Hegemonic masculinity & -0.31 & 0.17 & -0.13 & & \\
\hline Self-compassion & 0.40 & 0.07 & $0.40 * *$ & & \\
\hline Interaction term & -0.52 & 0.24 & $0.14 *$ & & \\
\hline \multicolumn{6}{|c|}{ Attitudes toward gay men (ATG-R-S5) } \\
\hline Step 1 & & & & $.17^{* *}$ & $.17^{* *}$ \\
\hline Hegemonic masculinity & 1.78 & 0.31 & $0.43 * *$ & & \\
\hline Self-compassion & 0.079 & 0.13 & 0.04 & & \\
\hline Step 2 & & & & $.19 *$ & $.02 *$ \\
\hline Hegemonic masculinity & 1.78 & 0.31 & $0.43 * *$ & & \\
\hline Self-compassion & 0.05 & 0.13 & 0.03 & & \\
\hline Interaction term & -0.92 & 0.44 & $-0.15^{*}$ & & \\
\hline \multicolumn{6}{|c|}{ Autonomy subscale of the SPWB } \\
\hline Step 1 & & & & $.25 * *$ & $.25^{* *}$ \\
\hline Inclusive masculinity & 0.21 & 0.07 & $0.22 * *$ & & \\
\hline Self-compassion & 0.39 & 0.07 & $0.38 * *$ & & \\
\hline Step 2 & & & & $.27 *$ & $.03 *$ \\
\hline Inclusive masculinity & 0.24 & 0.07 & $0.25^{* *}$ & & \\
\hline Self-compassion & 0.34 & 0.07 & $0.34 * *$ & & \\
\hline Interaction term & 0.26 & 0.11 & $0.17 *$ & & \\
\hline \multicolumn{6}{|c|}{ Attitudes toward gay men (ATG-R-S5) } \\
\hline Step 1 & & & & $.40^{* *}$ & $.40 * *$ \\
\hline Inclusive masculinity & -1.12 & 0.11 & $-0.66 * *$ & & \\
\hline Self-compassion & 0.18 & 0.11 & 0.11 & & \\
\hline Step 2 & & & & $.42 *$ & $.02 *$ \\
\hline Inclusive masculinity & -1.08 & 0.11 & $-0.64 * *$ & & \\
\hline Self-compassion & 0.13 & 0.11 & 0.07 & & \\
\hline Interaction term & 0.36 & 0.17 & $0.13 *$ & & \\
\hline
\end{tabular}

Note. SPWB = Scales of Psychological Well-Being; ATG-R-S5 = Attitudes Toward Gay Men revised subscale.

$* p<.05 . * * p<.01$.

the results of our moderation analyses. Our findings suggest that, for men athletes, having higher levels of self-compassion is related to a stronger negative relationship between hegemonic masculinity orientation and autonomy, and less negative attitudes toward gay men. Also, it appears that having relatively higher levels of selfcompassion enables men athletes of an inclusive masculinity orientation to have more positive attitudes toward gay men and higher levels of autonomy. Despite Wasylkiw and Clairo (2018) not finding significant moderation effects of self-compassion on the relationships between hegemonic masculinity and other variables, their findings showed that self-compassion moderated the relationship between the type of group (i.e., athletes, nonathletes) and helpseeking. Specifically, in a group of men athletes, higher levels of self-compassion were positively related to more favorable attitudes toward help-seeking, whereas in a group of (men) nonathletes, the self-compassion levels did not impact the levels of help-seeking. Thus, although the findings are inconsistent, when found to be a significant moderator in previous research, self-compassion seems to buffer unhealthy tendencies or traits and enhance healthy tendencies or traits, a pattern further supported by our findings.

\section{Limitations}

An implication of using a cross-sectional design is that there was no follow-up testing of variables in our study, meaning that any causal inferences related to the role of self-compassion need to be interpreted with significant caution. However, with our primary goals surrounding testing and replicating a wide range of variables/ reactions, a cross-sectional approach seemed the most appropriate and effective design at this stage of the research process. In addition, there was no preexisting scale specifically designed to measure inclusive masculinity, prior to our research. Accordingly, we developed the IMT, albeit with minimal evidence of construct validity and scale reliability (i.e., only the psychometric tests of the IMT in this study were available). Thus, all findings pertaining to inclusive masculinity, including significant relationships with other 
variables (e.g., self-compassion, hegemonic masculinity) and moderation analyses (e.g., self-compassion moderates relationship between inclusive masculinity and autonomy), are exclusive to this study and our use of the IMT.

Another limitation to this study is the presence of several potential confounding variables (e.g., maturation, type of sport, competitive level). Given the stage of research on men, masculinity, and self-compassion, we decided to recruit a diverse sample of men athletes. This decision has both strengths and weaknesses. A strength is that our results and findings are not specific to one type of sport or athlete, which is similar to much of the initial sport self-compassion research with women athletes (e.g., Mosewich et al., 2011). A weakness is that by having a wide range of athletes and sports, there is not sufficient data within any specific subsample for us to adequately explore how relationships might be similar or differ across different athletes and sports. For example, we defined an "athlete" as anyone who had competed in sport within the past 12 months at a level higher than recreational, which is consistent with previous self-compassion research with women athletes (e.g., Mosewich et al., 2011; Reis et al., 2015). However, elite international athletes might have very different "difficult experiences" in sport than even elite national-level athletes; hence, the level of sport might be particularly important to account for in future research on men athletes and selfcompassion.

The decision as to what psychosocial well-being variables to include and what variables to exclude was one of the most challenging aspects of our research. On one hand, the inclusion of a wide range of variables allowed us to address our primary goal, which was to explore the interaction of self-compassion and diverse versions of masculinity on the psychosocial well-being of men athletes. By capitalizing on what has already been learned in sport self-compassion research that has focused primarily on women athletes over the past decade, our hope is that our choice to include a wide range of variables will help accelerate the use of more advanced methods and designs in future research on men athletes and self-compassion. For example, a benefit of having a wide range of variables at this stage of research on men athletes' self-compassion is that our results can offer significant guidance in the choice of specific variables to include in future research, which will be particularly important to experimental research for which data collection typically requires substantial resources and occurs over multiple time points. On the other hand, a cost of the choice to include a wide range of psychological well-being variables is that we are not able to adequately provide in-depth insight into a smaller subset of variables that might be of particular interest to researchers working in a specific subdomain of men athletes, masculinity, and self-compassion (e.g., self-stigma of seeking help). In addition, because our questionnaire package was relatively long, consisted of a high number of scales and items, and was focused on the context of psychosocial well-being, some of the scales undoubtedly share construct overlap (e.g., it is not surprising that the SCS was related to state self-compassionate reactions to the hypothetical scenario). Our hope is that the wide breadth of our research will facilitate an increased focus on depth and complexity in research that follows. It is worth noting that early research on women athletes' self-compassion, including the first published study on women athletes' self-compassion (i.e., Mosewich et al., 2011), followed a similar path; thus, because relatively little is known about men athletes' self-compassion at present, particularly in the context of masculinity, we opted to follow that type of approach to our research as well.
Ultimately, we did our best to balance the need for a broad representation of variables, knowing that we still could not include all identified in previous research, against the potential for participant fatigue. Relatedly, the online platform we used to administer the questionnaire did not allow us a counterbalancing option; hence, it is unknown what, if any, role the order of the questionnaires played in the pattern of findings. We did, however, attempt to purposely order the measures in a way to try to reduce the consequences of fatigue (e.g., place measures of self-compassion and masculinity early in the questionnaire package). Another potential concern with the inclusion of a high number of variables is an increased probability of Type I error. However, although Type I error might be a concern, the overwhelming pattern of significant relationships gives us confidence in a conclusion supporting the relevance of self-compassion to the lives of men athletes. In addition, given that we are still in the relatively early stages of research on men athletes' selfcompassion, we were more concerned with making a Type II error (i.e., overlooking variables that might actually be critical to study in the area because of an overly conservative approach to significance). Despite this, even had we chosen a more conservative significance level (e.g., $p<.01$ ), there would have been little substantive change to any conclusions made related to the first two hypotheses (i.e., there were very few relationships significant at $p<.05$, but not at $p<.01)$. We feel the need to exercise more caution in the moderation analyses for which the number and magnitude of significant interactions was relatively small; hence, we are less confident with the role self-compassion might play specifically as a moderator variable in men's experiences in sport.

\section{Future Directions}

Despite our replication of many previous self-compassion findings in other samples (e.g., women athletes, nonathlete samples of men), we were, pragmatically, unable to include all variables that have been previously assessed in self-compassion research. Of note, in recent studies including both men athletes and women athletes, several variables were identified as related to self-compassion (e.g., adaptive coping, subjective well-being, social support, perfectionist strivings, perfectionist concerns, social physique anxiety, sport anxiety; Huysmans \& Clement, 2017; Jeon et al., 2016; Koc \& Ermis, 2016; Lizmore et al., 2017). Therefore, in future studies on self-compassion and exclusively men athletes, it is important to consider including not only the variables identified as significant in our research but also the entire range of variables that have been previously studied. Furthermore, although representation of an even wider range of previously identified relevant variables is a key future direction in research pertaining to men athletes' selfcompassion, there remains a lack of depth in the field, which might best be addressed through conversations with men athletes about self-compassion. Perhaps exploring men athletes' self-compassion through qualitative narratives, similar to Sutherland et al.'s (2014) approach with women athletes, might add a layer of depth to the current knowledge of men athletes' experiences of self-compassion. Specifically, it might provide an opportunity to not only explore how self-compassion might be related to sport-specific challenges of men athletes but also to better understand the seemingly inherent role of masculinity in men athletes' self-compassion.

Another foreseeable future step in the field of men athletes' self-compassion might be to develop a self-compassion intervention specifically tailored to men athletes, similar to what has been successfully accomplished with a population of women athletes 
(Mosewich et al., 2013). However, due to the seemingly integral role of masculinity in men athletes' difficult experiences in sport, and the possible complex relationship between self-compassion and masculinity (Mosewich et al., 2019), we recommend that masculinity be considered in the development of the proposed intervention. Perhaps a self-compassion intervention that also incorporates an element of inclusive masculinity might be more efficacious than an intervention focused on one or the other. When testing the effectiveness of a self-compassion intervention with men athletes, particularly one that integrates inclusive masculinity, the inclusion of a control group of men nonathletes will be important as a way to adequately test any uniqueness of selfcompassion to the context of men's sport. However, the most effective way to intervene is currently unknown, especially considering hegemonic-oriented men athletes' potential resistance to self-compassion (Mosewich et al., 2019). As noted by Mosewich et al. (2019), the adoption of self-compassion likely goes beyond simply introducing athletes to the approach; rather, it likely requires constructive reflection and acknowledgment of reluctance and challenges that athletes might associate with self-compassion. Thus, perhaps the abovementioned exploratory study on men athletes' narratives of self-compassion, with masculinity woven throughout, might be a valuable preemptive step for any selfcompassion intervention for men athletes.

\section{Acknowledgments}

This research was supported by the Social Sciences and Humanities Research Council of Canada (SSHRC), grant 862-2016-0004. The authors would like to acknowledge Dr. Eric Anderson for his help and support in developing the IMT.

\section{References}

Aiken, L.S., \& West, S.G. (1991). Multiple regression: Testing and interpreting interactions. Thousand Oaks, CA: Sage.

Anderson, E., \& McGuire, R. (2010). Inclusive masculinity theory and the gendered politics of men's rugby. Journal of Gender Studies, 19, 249-261. doi:10.1080/09589236.2010.494341

Connell, R.W., \& Messerschmidt, J.W. (2005). Hegemonic masculinity: Rethinking the concept. Gender \& Society, 19, 829-859. doi:10. $1177 / 0891243205278639$

Conroy, D.E., Willow, J.P., \& Metzler, J.N. (2002). Multidimensional fear of failure measurement: The performance failure appraisal inventory. Journal of Applied Sport Psychology, 14, 76-90. doi:10.1080/ 10413200252907752

Cvencek, D., Fryberg, S.A., Covarrubias, R., \& Meltzoff, A.N. (2018). Self-concepts, self-esteem, and academic achievement of minority and majority North American elementary school children. Child Development, 89, 1099-1109. PubMed ID: 28386954 doi:10.1111/ cdev.12802

del Rosario, P.M., \& White, R.M. (2006). The Internalized Shame Scale: Temporal stability, internal consistency, and principal components analysis. Personality and Individual Differences, 41, 95-103. doi:10. 1016/j.paid.2005.10.026

Eime, R.M., Young, J.A., Harvey, J.T., Charity, M.J., \& Payne, W.R. (2013). A systematic review of the psychological and social benefits of participation in sport for children and adolescents: Informing development of a conceptual model of health through sport. International Journal of Behavioral Nutrition and Physical Activity, 10, 1-21. doi:10.1186/1479-5868-10-1
Ferguson, L.J., Kowalski, K.C., Mack, D.E., \& Sabiston, C.M. (2014). Exploring self-compassion and eudaimonic well-being in young women athletes. Journal of Sport \& Exercise Psychology, 36, 203-216. PubMed ID: 24686956 doi:10.1123/jsep.2013-0096

Ferguson, L.J., Kowalski, K.C., Mack, D.E., \& Sabiston, C.M. (2015). Self-compassion and eudaimonic well-being during emotionally difficult times in sport. Journal of Happiness Studies, 16, 1263 1280. doi:10.1007/s10902-014-9558-8

Fontana, M.S., Fry, M.D., \& Cramer, E. (2017). Exploring the relationship between athletes' perceptions of the motivational climate to their compassion, self-compassion, shame, and pride in adult recreational sport. Measurement in Physical Education and Exercise Science, 21, 101-111. doi:10.1080/1091367X.2017.1278698

Gilbert, P., McEwan, K., Matos, M., \& Rivis, A. (2011). Fears of compassion: Development of three self-report measures. Psychology and Psychotherapy: Theory, Research and Practice, 84, 239-255. doi:10.1348/147608310X526511

Gilbert, P., \& Procter, S. (2006). Compassionate mind training for people with high shame and self-criticism: Overview and pilot study of a group therapy approach. Clinical Psychology \& Psychotherapy, 13, 353-379. doi:10.1002/cpp.507

Gotwals, J.K., \& Dunn, J.G.H. (2009). A multi-method multi-analytic approach to establishing internal construct validity evidence: The Sport Multidimensional Perfectionism Scale 2. Measurement in Physical Education and Exercise Science, 13, 71-92. doi:10.1080/ 10913670902812663

Herek, G.M. (1984). Attitudes toward lesbians and gay men: A factoranalytic study. Journal of Homosexuality, 10, 39-51. PubMed ID: 6520388 doi:10.1300/J082v10n01_03

Herek, G.M. (1997). The attitudes toward lesbians and gay men (ATLG) scale. In C.M. Davis, W.H. Yarber, R. Bauserman, G. Schreer, \& S.L. Davis (Eds.), Sexuality-related measures: A compendium. Thousand Oaks, CA: Sage Publications.

Huysmans, Z., \& Clement, D. (2017). A preliminary exploration of the application of self-compassion within the context of sport injury. Journal of Sport \& Exercise Psychology, 39, 56-66. PubMed ID: 28169571 doi:10.1123/jsep.2016-0144

Jeon, H., Lee, K., \& Kwon, S. (2016). Investigation of the structural relationships between social support, self-compassion, and subjective well-being in Korean elite student athletes. Psychological Reports, 119, 39-54. PubMed ID: 27381414 doi:10.1177/0033294116658226

Koc, H.E., \& Ermis, E. (2016). Self-compassion as a predictor of social physique anxiety in athletes. Journal of Human Sciences, 13, 5214-5222. doi:10.14687/ijhs.v13i1.3618

Leary, M.R. (1983). A brief version of the Fear of Negative Evaluation scale. Personality and Social Psychology Bulletin, 9, 371-375. doi:10.1177/0146167283093007

Leary, M.R., Tate, E.B., Adams, C.E., Allen, A.B., \& Hancock, J. (2007). Self-compassion and reactions to unpleasant self-relevant events: The implications of treating oneself kindly. Journal of Personality and Social Psychology, 92, 887-904. PubMed ID: 17484611 doi:10. 1037/0022-3514.92.5.887

Lizmore, M.R., Dunn, J.G.H., \& Dunn, J.C. (2017). Perfectionist strivings, perfectionist concerns, and reactions to poor personal performance among intercollegiate athletes. Psychology of Sport and Exercise, 33, 75-84. doi:10.1016/j.psychsport.2017.07.010

Mesagno, C., Harvey, J.T., \& Janelle, C.M. (2012). Choking under pressure: The role of fear of negative evaluation. Psychology of Sport and Exercise, 13, 60-68. doi:10.1016/j.psychsport.2011. 07.007

Mosewich, A.D., Crocker, P.R.E., Kowalski, K.C., \& DeLongis, A. (2013). Applying self-compassion in sport: An intervention with 
women athletes. Journal of Sport \& Exercise Psychology, 35, 514-524. PubMed ID: 24197719 doi:10.1123/jsep.35.5.514

Mosewich, A.D., Ferguson, L.J., McHugh, T.-L.F., \& Kowalski, K.C. (2019). Enhancing capacity: Integrating self-compassion in sport. Journal of Sport Psychology in Action, 10(4), 235-243. doi:10.1080/ 21520704.2018.1557774

Mosewich, A.D., Kowalski, K.C., Sabiston, C.M., Sedgwick, W.A., \& Tracy, J.L. (2011). Self-compassion: A potential resource for young women athletes. Journal of Sport \& Exercise Psychology, 33, 103-123. PubMed ID: 21451173 doi:10.1123/jsep.33.1.103

Neff, K.D. (2003a). Development and validation of a scale to measure self-compassion. Self and Identity, 2, 223-250. doi:10.1080/ 15298860309027

Neff, K.D. (2003b). Self-compassion: An alternative conceptualization of a healthy attitude toward oneself. Self and Identity, 2, 85-101. doi:10. 1080/15298860309032

Oja, P., Titze, S., Kokko, S., Kujala, U.M., Heinone, A., Kelly, P., . . . Foster, C. (2015). Health benefits of different sport disciplines for adults: Systematic review of observational and intervention studies with meta-analysis. British Journal of Sports Medicine, 49, 434-440. PubMed ID: 25568330 doi:10.1136/bjsports-2014-093885

Parent, M.C. (2013). Handling item-level missing data: Simpler is just as good. The Counseling Psychologist, 41, 568-600. doi:10.1177/ 0011000012445176

Parent, M.C., \& Moradi, B. (2009). Confirmatory factor analysis of the Conformity to Masculine Norms Inventory and development of the Conformity to Masculine Norms Inventory-46. Psychology of Men \& Masculinity, 10, 175-189. doi:10.1037/a0015481

Puterman, E., DeLongis, A., \& Pomaki, G. (2010). Protecting us from ourselves: Social support as a buffer of trait and state rumination. Journal of Social \& Clinical Psychology, 29, 797-820. doi:10.1521/ jscp.2010.29.7.797
Reid, R.C., Temko, J., Moghaddam, J.F., \& Fong, T.W. (2014). Shame, rumination, and self-compassion in men assessed for hypersexual disorder. Journal of Psychiatric Practice, 20, 260-268. PubMed ID: 25036581 doi:10.1097/01.pra.0000452562.98286.c5

Reilly, E.D., Rochlen, A.B., \& Awad, G.H. (2013). Men's self-compassion and self-esteem: The moderating roles of shame and masculine norm adherence. Psychology of Men \& Masculinity, 15, 22-28. doi:10. 1037/a0031028

Reis, N.A., Kowalski, K.C., Ferguson, L.J., Sabiston, C.M., Sedgwick, W.A., \& Crocker, P.R.E. (2015). Self-compassion and women athletes' responses to emotionally difficult sport situations: An evaluation of a brief induction. Psychology of Sport and Exercise, 16, 18-25. doi:10.1016/j.psychsport.2014.08.011

Rosenberg, M. (1965). Society and the adolescent self-image. Princeton, NJ: Princeton University Press.

Ryff, C.D., \& Keyes, C.L.M. (1995). The structure of psychological well-being revisited. Journal of Personality and Social Psychology, 69, 719-727. PubMed ID: 7473027 doi:10.1037/0022-3514.69. 4.719

Sutherland, L.M., Kowalski, K.C., Ferguson, L.J., Sabiston, C.M., Sedgwick, W.A., \& Crocker, P.R.E. (2014). Narratives of young women athletes' experiences of emotional pain and self-compassion. Qualitative Research in Sport, Exercise and Health, 6(4), 499-516. doi:10.1080/2159676X.2014.888587

Tabachnick, B.G., \& Fidell, L.S. (2013). Using multivariate statistics (6th ed.). Boston, MA: Pearson.

Vogel, D.L., Wade, N.G., \& Haake, S. (2006). Measuring the self-stigma associated with seeking psychological help. Journal of Counseling Psychology, 53, 325-337. doi:10.1037/0022-0167.53.3.325

Wasylkiw, L., \& Clairo, J. (2018). Help seeking in men: When masculinity and self-compassion collide. Psychology of Men \& Masculinity, 19(2), 234-242. doi:10.1037/men0000086 